\title{
Coronary artery fistula in a patient with coronary artery disease: evaluation by coronary angiography and multidetector computed tomography
}

Fuat Gundogdu • Sakir Arslan •

Eyup Buyukkaya $\cdot$ Mecit Kantarci

Published online: 19 January 2007

(C) Springer Science+Business Media B.V. 2007

\section{Erratum to: Int J Cardiovasc Imaging DOI 10.1007/s10554-006-9146-z}

In the original publication of this article, the fourth author's name was missing. The complete list of authors is given below.

Fuat Gundogdu, Sakir Arslan, Eyup Buyukkaya and Mecit Kantarci

The online version of the original article can be found at http://dx.doi.org/10.1007/s10554-006-9146-z

F. Gundogdu ( () ) S. Arslan · E. Buyukkaya . M. Kantarci Department of Cardiology, School of Medicine, Ataturk University, Erzurum 25070, Turkey e-mail: gundogdudr@gmail.com 